\title{
Trabalho e suicídio: gesto de resistência final
}

\author{
Work and suicide: an ultimate resistance gesture
}

\section{Trabajo y suicidio: el último gesto de resistencia}

\section{Luciene J ung de Campos*}

Universidade de Caxias do Sul - UCS, Caxias do Sul, Rio Grande do Sul, Brasil

\section{Raquel Alquatti**}

Universidade de Caxias do Sul - UCS, Caxias do Sul, Rio Grande do Sul, Brasil

\section{Stefany Rettore Garbin***}

Universidade de Caxias do Sul - UCS, Caxias do Sul, Rio Grande do Sul, Brasil

\section{I smael Pereira****}

Universidade de Caxias do Sul - UCS, Caxias do Sul, Rio Grande do Sul, Brasil

\begin{abstract}
RESUMO
O artigo propõe um gesto de leitura de três processos judiciais sobre suicídio e trabalho. Os casos levantados junto ao Memorial do Judiciário do Estado do Rio Grande do Sul correspondem às décadas de 1960 e 1970. Apresentados aqui na interface entre as duas disciplinas de origem dos autores, Psicologia e História, e entre duas obras: Suicídio e Trabalho: o que fazer? de Christophe Dejours e Florence Bègue (2010) e Sobre o Suicídio de Karl Marx (1846/2006). A Análise de Discurso é o dispositivo teórico analítico que proporciona essa interface sendo conhecimento de entremeio entre Psicanálise, Materialismo Histórico e Linguagem, através do qual procuramos analisar os efeitos de evidência presentes nos processos judiciais. O que quer saber um processo criminal de suicídio? Observamos que os processos trabalhados procuram cúmplices e culpados encarnados. $\mathrm{O}$ suicídio é um gesto absoluto e silenciado, tratado como um ato individual e, portanto, atribuído ao seu autor. Pouco se discute acerca do suicídio ou da situação em que é praticado. Menos ainda, a relação do suicídio com a sociedade em que é concebido. Perde-se o sujeito que engendra o gesto. Resta o sujeito autor na condição de depositário: causa e consequência de sua própria ação.
\end{abstract}

Palavras-chave: trabalho, suicídio, análise de discurso, psicodinâmica do trabalho.

\section{ABSTRACT}

This article proposes a reading gesture of three lawsuits about work and suicide. The cases from 1960s and 1970s were found in the collection from Rio Grande do Sul State Judiciary Memorial. As a dialogue between Psychology and History, the lawsuits are read among two different works, Suicide et travail: que faire? by Christophe Dejours e Florence Bègue (2010) 
and "About the Suicide" by Karl Marx (1846/2006). Discourse Analysis is the theoretic analytical device interfacing with Psychoanalysis, Historical Materialism and the Language, through what we sought analyze the evidence effects in the lawsuits. However, what a lawsuit about suicide wants to know? We have seen that the investigated lawsuits are searching for accomplices or an incarnate guilty. Suicide is an absolute and muted gesture. Historically it has been treated as individual act and, therefore, assigned by his author. The suicide or the situation where it was practiced has a short discussion, even shorter is the relation made between the suicide and society where it comes from. The subject whom engenders the gesture gets lost. Remains the author subject in the receiver condition: cause and consequence of his own action.

Keywords: work, suicide, discourse analysis, psychodynamics of work.

\section{RESUMEN}

El presente artículo expone la lectura de tres procedimientos judiciales sobre suicidio y trabajo. Los casos recogidos en el Memorial Judicial del Estado de Río Grande del Sur corresponden a las décadas de los 1960 y 1970. Presentados en la interfaz entre las dos disciplinas de origen de los autores, Psicología e Historia y entre dos obras, Trabajo y Suicidio de Christophe Dejours y Florence Bègue (2010) y Acerca del suicidio de Karl Marx (1846/2006). El Análisis del Discurso es el dispositivo teórico analítico que proporciona este interfaz, siendo el conocimiento puente entre Psicoánalisis, Materialismo histórico y Lenguaje, a través del cual procuramos analizar las evidencias presentes en los procesos judiciales. ¿Qué es lo que se quiere saber de un proceso criminal de suicidio? Observamos que los procesos trabajados hacen una búsqueda encarnada de cómplices y culpables. El suicidio es un acto absoluto y silenciado, tratado como un acto individual y, por tanto, atribuído a su autor. Pocas son las discusiones acerca del suicidio o de la situación en la que es practicado. Menos todavía, la relación del suicidio con la sociedad en la que es concebido. Se pierde el sujeto que engendra el acto. Falta el sujeto autor en la condición de receptor: causa y consecuencia de su propio acto.

Palabras clave: trabajo, suicidio, análisis del discurso, psicodinámica del trabajo.

\section{I ntrodução}

É a leitura da obra Suicídio e Trabalho: o que fazer?, de Christophe Dejours e Florence Bègue, publicado no ano de 2010, que, inicialmente, nos provocou indagações e discussões sobre os impactos do trabalho no ato do suicídio, rompendo com a dissimulação capitalista e patriarcal - portanto social - no envolvimento com esse ato último. Essa obra contemporânea nos fez buscar na memória outros já-ditos e inclinou a nossa atenção a uma leitura clássica: Sobre o Suicídio, de Karl Marx, publicado originalmente em 1846. Passados 164 anos entre as respectivas obras, as interfaces entre elas são múltiplas e possibilitam um amplo campo de agenciamentos e controvérsias. 
Para introduzir esta breve discussão, propomos um diálogo entre o referencial teórico e três casos de suicídio obtidos no acervo do Memorial do Judiciário do Estado do Rio Grande do Sul, estabelecido desde 2002 em parceria com o Tribunal de Justiça do Estado do Rio Grande do Sul. O Memorial possui em seu acervo histórico, documental, imagético e audiovisual, processos completos de primeira e de segunda instância. No ano de 2012 nem todo o material do acervo encontrava-se catalogado, portanto, a pesquisa esteve limitada por aquilo que já se encontrava na base de dados do memorial.

Sobre esta base de dados, realizou-se uma consulta geral através da palavra-chave 'suicídio' em todo material até então catalogado. Foram selecionados três casos dados como encerrados em primeira instância, que apresentaram relação ao contexto de trabalho, ocorridos nas décadas de 1960 e 1970 em Caxias do Sul.

Estes processos serão tomados como textos a partir da perspectiva teórico-analítica da Análise de Discurso de vertente francesa (AD). Apresentamos, portanto, dois movimentos: uma interface entre as perspectivas de Marx e Dejours e Bègue os casos de suicídio, costurados a partir da perspectiva da AD.

$\mathrm{Na}$ articulação entre diferentes saberes, buscamos construir um olhar outro ao suicídio, a partir do referencial teórico da psicodinâmica do trabalho, realizando uma interface com a obra do filósofo alemão Karl Marx, e também com a perspectiva de análise judicial do historiador Sidnei Chalhoub (2001). Recusamos, contudo, o conceito de interdisciplinaridade, onde uma disciplina é instrumentalizada pela outra. Propomos trabalhar nos entremeios dos saberes, nos campos de contradição, aproveitando a outra disciplina, ao revés (Orlandi, 1996).

\section{Entremeio de saberes, dispositivos para olhar o suicídio}

Ao indicarmos que este trabalho lida com os entremeios de disciplinas e autores que colocamos em diálogo, será a Análise de Discurso (AD) - uma disciplina de fronteiras - que nos auxiliará a fazer os nós entre campos do saber. Esta disciplina consolida-se nos anos 60 na França, tendo como principal representante Michel Pêcheux.

A Análise do Discurso situa-se na contradição entre a linguística, o materialismo histórico e a psicanálise (Orlandi, 1996). É nessa contradição que a língua é tomada como prática. "É a ação que transforma, que constitui identidades. Ao falar, ao significar eu me significo" (Ibidem, 1996, p. 28). De acordo com Orlandi (1996), é através da ideologia que são produzidos os efeitos de evidência que sustentam os sentidos, como se pertencessem a uma ordem lógica, óbvia e natural. A AD busca desconstruir tais evidências do discurso, 
apontando para a ideologia como constitutiva de sujeitos e sentidos que se produzem no movimento entre a língua e a história.

Desta forma, propor um diálogo entre a Análise de Discurso, psicodinâmica do trabalho, escritos marxistas e história, não sugere fazer-nos circular por campos desconhecidos, pelo contrário, os saberes aqui articulados se relacionam em um contínuo movimento, buscando abarcar os processos sociais que constroem os significados e os sujeitos.

Nesta lógica, tomaremos as fontes criminais como texto. Para a AD o texto é uma unidade de análise, feita de som, letra, imagem, começo, meio e fim. Orlandi (2001) concebe que o texto é a linearização do discurso ao passo que o materializa, com ordem e direção. Cabe ressaltar, de forma abreviada, que o discurso é tomado aqui como materialidade da ideologia. O texto, contudo, implica uma autoria em sua origem que o dê coerência, progressão e finalidade.

A $A D$ pressupõe um texto que não está fechado em si, mas abre-se enquanto objeto simbólico para diferentes leituras. "Isso mostra, por sua vez, a relação da língua com a história, que não é perfeitamente articulada, resultando de um jogo sobre a própria língua, face a sua inscrição na história" (Orlandi, 2001, p. 64). Produz-se então o efeito-leitor no espaço entre os sentidos, a memória e o texto.

Orlandi (2001) aponta, portanto, que não é o texto que dá as possibilidades de sua leitura, mas é no espaço construído no entremeio do texto e do discurso que podem emergir os gestos de leitura. "Ler é fazer um gesto de interpretação configurando este gesto na política da significação" (idem, p.68). É por haver este espaço simbólico aberto que poderemos gerar significações a partir do modo em que o discurso faz-se enquanto texto. "Há textos possíveis nas margens do texto" (I bdem, p. 65).

Ao tomar fontes criminais como texto, buscamos romper com os sentidos tidos como evidentes, atrelados ao ato suicida pelas instâncias jurídicas. Portanto, pretendemos indagar quais as condições de produção dos discursos relacionados aos sujeitos e ao trabalho nestes processos. Entendemos que as fontes criminais não servem apenas ao estudo das representações jurídicas. Ler e analisar processos criminais possibilita a identificação de trabalhadores e trabalhadoras agindo e descrevendo os sentidos de suas relações fora das instituições oficiais (Chalhoub, 2001).

Admitimos a impossibilidade de conhecimento sobre a sequência de fatos que antecede o ato suicida e nem é esta a pretensão desse trabalho. Mas é preciso destacar que há uma diferença explícita entre os processos criminais em geral e os processos criminais de suicídio. Nos processos criminais em geral buscam-se as causas da morte ligadas ao outro. Porém, nos casos de suicídio pesquisados, a responsabilidade da morte é tão e somente do próprio morto e isso 
não está explicito apenas no processo judicial, mas na forma como a maioria das sociedades ao longo da história lidam com o suicídio.

Nesta pesquisa, a busca dos textos jurídicos foi realizada na base de dados do acervo do Memorial do Judiciário do Estado do Rio Grande do Sul pelo termo "suicídio" e dentre todos os resultados (em média 30 processos) foram escolhidos aqueles que aconteceram ou tinham relação com o local de trabalho. O trâmite legal de acesso aos documentos consistiu em um primeiro contato entre pesquisadores e responsáveis pelo acervo, sendo apresentada documentação comprobatória de vinculação institucional e projeto de pesquisa. Feito isso, tivemos acesso a documentação. Selecionados os documentos, preenchemos uma ficha solicitada pelo Memorial de compromisso de utilização dos documentos apenas para objetivos de estudo e pesquisa, e onde, pela proximidade temporal, não nos é autorizada a utilização dos nomes próprios do processo.

Encontramos um processo da década de sessenta e dois da década de setenta. Embora, o memorial encontre-se em processo de catalogação, a presente pesquisa não tem intenção de analisar quantitativamente os processos de tal acervo. Selecionamos os três processos que tangenciam, por assim dizer, a relação com o trabalho. A principal questão metodológica foi como ler e como interpretar tais processos. De acordo com Chalhoub (2001):

Em um processo diversas versões são produzias e a verdade são as relações sistematicamente repetidas, ou seja, a verdade é a verdade reconhecida. Ler processos criminais não significa partir em busca "do que realmente se passou" porque esta seria uma expectativa inocente [...] O importante é estar atento às "coisas" que se repetem sistematicamente: versões que se reproduzem muitas vezes, aspectos que ficam mal escondidos, mentiras ou contradições que aparecem com frequência (p. 41).

Desta perspectiva é que verificamos algumas semelhanças entre os processos e chegamos à seguinte questão: se, como já apontamos, no processo não se almeja falar do suicídio, o que busca um processo criminal sobre o mesmo? Na continuidade da pesquisa histórica não encontramos versões nos jornais. Existem poucas testemunhas nos processos e elas pouco sabem ou não notaram nada. Assim, mais do que entender os sentidos das falas do processo é preciso entender o sentido do não dito: do silêncio. Segundo Orlandi (1997), é importante perceber que há silêncio nas palavras e que o não dito é absolutamente diferente do implícito, o silenciamento é um "pôr em silêncio" (Orlandi, 1997). E ainda: "O silêncio não é o vazio, o semsentido; ao contrário, ele é o indício de uma totalidade significativa. 
Isto nos leva à compreensão do "vazio" da linguagem como um horizonte e não como falta" (Orlandi, 1997, p. 70).

Carregando a história de sua própria sobrevivência como documento, o processo criminal permite uma aproximação entre História e Direito onde é possível ampliar o objeto de investigação percebendo a relação entre o Estado e os sujeitos e as concepções de lei e justiça. É possível ainda, traçar uma história da criminalidade, do cotidiano e, neste caso, do suicídio. Os processos judiciais são uma mistura de documento oficial e declaração oral. Mas são muito mais específicos, já que os declarantes estão sob olhar do Estado. Os textos que daí decorrem são os mais diversos, sendo possível observar o que foi perguntado, o que foi dito, os laudos oficiais e, por fim, a interpretação do judiciário. A mediação entre essas disciplinas permite problematizar o funcionamento da ideologia no discurso legal e na memória.

\section{Resenha dos processos}

Sem extensão analítica, apresentamos brevemente os três casos:

\section{Caso 1}

O primeiro caso apresentado, em ordem cronológica, foi um suicídio por arma de fogo de uma mulher em 1968 na Zona do Meretrício de Caxias do Sul, conhecida assim por abrigar a maioria das casas de prostituição do período. O processo possui três fotografias de perícia e sete declarações de testemunhas. O caso acontece dentro de uma determinada pensão, não fica clara a função dessa mulher e há muitas pessoas que presenciam o suicídio.

A mãe (que a mulher teria chamado para ir ao seu encontro na pensão), o patrão que, de acordo com depoente do processo supostamente seria o amante da vítima, e uma colega. Havia pessoas no salão durante o ocorrido e foram chamados também vizinhos para depor. Em nenhum momento é averiguada a causa do suicídio. Procura-se saber onde estava a arma, onde estavam as pessoas, como aconteceu - a sequência dos fatos.

Qualquer detalhe sobre o processo é obtido nos depoimentos, em que essa mulher é caracterizada como perturbada, estando muito ansiosa quando do ocorrido, chegando a ser citada sua alteração emocional devido à ingestão de vinho durante seu ciclo menstrual.

\section{Caso 2}

O segundo caso é de um homem morto por envenenamento em 1972. Descrito como branco, solteiro (amasiado), comerciário de 22 anos. São arrolados os depoimentos do pai, da mãe, da mulher com 
quem vivia e ele deixa também pequenos bilhetes. Já havia tentado envenenar-se oito dias antes quando foi internado.

O sujeito deixa um bilhete forjado, de sua mulher para uma amiga, pedindo ajuda, o que indica um planejamento do suicídio e uma preocupação com a mulher com quem ele era amasiado. Deixa um bilhete endereçado a ela, escrito a mão, jurando amor e dizendo que "já não era possível suportar". E outro bilhete ao pai, pedindo perdão, dizendo que já deu muito desgosto, pedindo que ele desculpe a mãe pelo que ele acha que ela fez. Todos esses bilhetes são encontrados junto com o corpo.

A mulher, de forma fragmentada, diz que ele vivia muito fora de casa; que ela não tinha nada a alegar contra ele; que ele não dizia onde andava; que nunca havia falado com ela sobre suicídio; que vivia sempre alegre; ela não sabia se ele costumava frequentar a Zona do Meretrício.

No depoimento do pai há poucas informações, ele relata que o filho vivia no jogo, que tinha dívidas e que já havia tentado suicídio. De acordo com o processo, o sujeito vivia constantemente fora dos preceitos sociais, na expressão legal, era um boêmio. Recolhidos todos esses depoimentos e constatado o suicídio, o caso é encerrado.

\section{Caso 3}

Um enforcamento de um homem de 55 anos no interior de seu bar em 1974. Segundo depoimento de um cliente que costumava tomar café no bar e encontrou-o. Quando o cliente chegou, a porta estava fechada e havia fumaça da cafeteira. Eles se conheciam há oito anos, mas o depoente não sabia a causa da morte. O balconista do bar afirmou que não sabia os motivos do suicídio, que o patrão estava cada vez mais doente e que tremia muito. Por fim a declaração da esposa que explicou a doença do marido (esclerose cerebral) e pouco conseguiu falar no depoimento.

A conclusão do processo é a seguinte: "trata-se de suicídio inexistindo qualquer elemento para caracterizar crime previsto no Artigo 122 do Código Penal, seja induzimento, instigação ou auxilio ao suicídio, peço arquivamento do inquérito. Conclui-se que foi levado a suicídio devido à grave enfermidade que sofria".

Após breve apresentação dos três casos, algumas indagações ecoam pelos entremeios das disciplinas, anteriormente mencionadas. A explorá-las, o ensaio de alguns conceitos fundamentais, primeiramente, nos é necessário. O entendimento das relações entre trabalho e suicídio, bem como a observação das análises dos autores e a aproximação que eles fazem de seus casos com o contexto social e político, oferecem suporte para que tracemos reflexões sobre os casos levantados. 


\section{Trabalho, suicídio e resistência}

A partir de um referencial dejouriano, podemos realizar uma retomada conceitual ao enredo das patologias vinculadas à saúde do trabalhador. Faz-se necessário partirmos de uma premissa apontada por Dejours e Bègue (2010): "o trabalho desempenha um papel protagonista tanto na construção da saúde como na construção da economia das relações na esfera privada" (p.29). Deste modo, abordar o suicídio em uma esfera trabalhista escancara uma posição teórica que rompe com os pactos de silêncio, pois "as investigações sobre suicídio, e tudo o que precedeu o trágico desfecho, terminam geralmente, antes mesmo de iniciadas" (Ibidem, p.13).

Na obra Suicídio e Trabalho: o que fazer, Dejours e Bègue (2010) incitam que a complexa teia da atividade do trabalho propicia o surgimento de situações que, para psicopatologia do suicídio, sempre constituiu uma tarefa clínica difícil. O que se busca é colocar em análise a força de resistência que os suicídios no trabalho imprimem.

Se fica acertado para Dejours e Bégue (2010) que os gestos suicidas incidem tanto sobre populações atingidas pelo desemprego quanto como uma saída para problemas no trabalho, podemos tentar compreender as nuances de sofrimento do trabalho e de seu reverso, pois ao homem que não trabalha é também destinado os efeitos de uma exclusão social ou de um sentimento de não pertencimento.

Para Dejours e Bègue (2010) é claro que a condição de submissão ao trabalho torna suscetível a expressão da violência, aos outros ou a si. São as estratégias coletivas de defesa que podem dar conta de combater 0 sofrimento no trabalho: "uma dramaturgia que metamorfoseava o sofrimento e a dor em escárnio e excluía qualquer comportamento ambíguo que poderia evocar o medo" (p.16).

Um acidente de trabalho desestabiliza as relações com a estratégia coletiva de defesa. Esta será desqualificada pelo acidente, e o risco volta à consciência. "E com a consciência do risco, volta o medo" (Ibidem, p. 16). O medo deve voltar mascarado e irreconhecível, sob a forma de sintoma médico e não psicológico.

A exclusão ou fim do sentimento de pertencimento à comunidade constituída pelos profissionais dos diferentes ofícios da construção civil implicaria no questionamento, pelo operário, de todo o seu passado, até mesmo de sua biografia social e profissional e, consequentemente, de sua própria identidade (Dejours \& Bégue, 2010, p.19).

O suicídio, para os autores, dispõe-se como uma conduta endereçada, uma mensagem "contra toda expressão de sofrimento no teatro do trabalho" (Dejours \& Bégue, 2010, p.20). O local do ato suicida, praticado fora do local do trabalho, indicaria assim, uma 
forma de canalização do sofrimento para fora "pressionado por um último resquício ou pudor, socialmente construído" (Dejours \& Bégue, 2010, p.20), - talvez, para preservar os resquícios de coletividade defensiva. Em seu oposto - quando o suicídio é cometido dentro do local do trabalho -, pode indicar uma degradação do viver-junto, onde as condutas de solidariedade já se tornaram extremamente enfraquecidas. $O$ ato, deste modo, indica que toda a comunidade de trabalho já está sofrendo.

Que um suicídio possa ocorrer no local de trabalho indica que todas essas condutas de ajuda mútua e solidariedade - que não era nem mais nem menos que uma simples prevenção das descompensações, assumidas pelo coletivo de trabalho - foram banidas dos costumes e da rotina da vida de trabalho. Em seu lugar, instalou-se a nova fórmula do cada um por si; e a solidão de todos tornou-se regra. Agora, um colega afoga-se e não se lhe estende mais a mão (Dejours \& Bégue,2010, p. 21).

Neste sentido, normalmente, a diretoria das empresas busca isentarse de sua responsabilidade, imputando, geralmente, o gesto suicida a um "temperamento" depressivo ou psicopatológico próprio ao suicida, ou ainda a conflitos afetivos que o mesmo desenvolvia na esfera privada. Se as empresas já fazem a manobra de negar o sofrimento do trabalhador, por que a perícia policial não faria o mesmo e, principalmente, com o suicídio? Não é apenas o setor privado que assume essa postura. O Estado, representado pelo judiciário, também efetua uma omissão ao privatizar o ato suicida ao sujeito. Esse gesto colabora para a marginalização do suicídio, o que faz com que ele seja pouco investigado, ou pior, completamente esquecido e depositado, apenas, na vontade do sujeito de tirar a própria vida. Assim, a escolha foi dele e apenas a ele interessa.

Em consonância com tais conceitos é possível abarcar a publicação Sobre o Suicídio (2006 [1818-1883]). Nesta obra, Marx comenta os escritos do arquivista policial Jacques Peuchet, em sua experiência à frente da investigação policial francesa. A publicação original, datada de 1846, traz as impressões de Marx sobre as causas e processos sociais do suicídio.

O emblema desta obra perpassa o suicídio como um sintoma de uma sociedade de classes. Se, de acordo com Marx, sociedades diferentes, geram produtos diferentes, o suicídio é um sintoma em todas as classes, proveniente de uma organização social capitalista. "Está na natureza de nossa sociedade gerar muitos suicídios, ao passo que os tártaros não se suicidam. As sociedades não geram todas, portanto, os mesmos produtos" (p.25, grifos do autor).

O autor aponta que o discurso que circunda o tema, vem no sentido de realizar uma culpabilização dos sujeitos: "[...] faz-se do suicídio 
um ato de covardia, um crime contra as leis, a sociedade e a honra" (Marx, 2006, p.26). Também os inquéritos buscam a culpabilização de outro sujeito, já que voltar-se para as causas sociais é inviável. Para Marx, o que se coloca no cerne deste sintoma social são as relações de poder, como aponta no seguinte trecho: [...] descobri os maus-tratos como o fator dominante, as injustiças, os castigos secretos, que pais e superiores impiedosos infligem sobre as pessoas que encontram sob sua dependência (Marx, 2006, p.28).

Retomamos aqui o questionamento deixado em suspenso no título: por que resistência? É a partir dos escritos marxistas, publicados há mais de cem anos antes das teorizações dejourianas, que encontramos vestígios. "Tudo o que se disse contra o suicídio gira em torno do mesmo círculo de ideias. A ele são contrapostos os desígnios da Providência, mas a própria existência do suicídio é um notório protesto contra esses desígnios ininteligíveis" ( $p$. 26, grifos do autor).

E ainda:

As relações entre os interesses e os ânimos, as verdadeiras relações entre os indivíduos ainda estão para ser criadas entre nós inteiramente, e o suicídio não é mais do que um entre os mil e um sintomas da luta social geral, sempre percebida em fatos recentes, da qual tantos combatentes se retiram porque estão cansados de serem contados entre as vítimas ou porque se insurgem contra a ideia de assumir um lugar honroso entre os carrascos (p. 29, grifo do autor).

O suicídio é revestido de resistência quando se desloca da fraqueza, da doença, do privado e toma a forma do protesto, da mensagem, da autoria. Ato de resistência às condições tão opressivas que impelem o sujeito a retirar-se da cena. Este deslocamento, contudo, é um deslocamento de significados, uma forma de tradução da mensagem revestida de silêncio. Dejours e Bègue (2010) preconizam a ideia de que é pela palavra que o implacável silêncio pode tomar forma de pensamento. Pensaremos aqui um dos lugares onde essa fala é autorizada: o discurso judiciário.

\section{O suicídio e a ordem dos fatos: a falha do sentido}

Se relacionarmos os casos citados ao que foi debatido até agora, poderemos traçar um percurso de questionamentos diferentes daqueles feitos nos respectivos processos, em uma tentativa de romper com os efeitos de evidência. É necessário que apontemos primariamente a noção de justiça que será utilizada neste trabalho. Barros (1997) compreende que: 
A justiça enquanto ideal é uma ficção, cada um tem uma ideia sobre isso... Basta perguntar o que é Justiça que encontraremos uma infinidade de arranjos simbólicos tentando definir tal conceito que permanece inatingível enquanto algo objetivável, sendo sempre na ordem do singular a sua apropriação. O sujeito jurídico e a justiça são noções ideológicas e ficcionais (p. 41).

O discurso judiciário é representante de uma parcela do Estado no momento em que emite um saber sobre o modo em que os casos devem ser tratados. Contudo, os processos são literaturas ficcionais, como relata Barros (1997), onde versões estão em jogo para construir uma verdade sobre algo.

Começaremos pelo último caso exposto, pois ele diz muito sobre os anteriores. Ao menos duas conclusões podem ser retiradas do rápido arquivamento do processo e a mais importante é que o inquérito sobre o suicídio, assim como nos outros casos, é aberto apenas para averiguar a participação ou envolvimento de alguém no acontecimento. Ou seja, se quer saber apenas da cumplicidade no ato. Segundo, rapidamente conclui-se que o mesmo suicidou-se pela sua enfermidade e pouco mais se investiga sobre o caso. Fica a dúvida: o que torna o bar palco do ato final? As investigações sobre o suicídio, e tudo o que precedeu o trágico desfecho, terminam, geralmente, antes mesmo de iniciadas.

Esse caso se aproxima muito da perspectiva trazida por Dejours e Bègue (2010) que apontam para um silenciamento do medo. Mesmo admitindo que o único motivo do suicídio fosse a esclerose de que padecia o dono do bar, questiona-se ainda que tipo de sofrimento essa doença infligia ao mesmo, já que o suicídio aconteceu - ou seja, foi endereçado - no local de trabalho. Quais sentidos são postos frente à morte na cena do trabalho? Se a resposta é realmente a doença física, particular, isolada, então, como o bar? Como não no privado, na casa?

Pêcheux (1997) ressalta que a evidência, por exemplo, de que "eu seja realmente eu" é produzida através de uma interpelaçãoidentificação. A lei jurídica, deste modo, apontará para: [...] 'aquele que pode causar um dano...' (e a lei sempre encontra 'um jeito de agarrar alguém', uma 'singularidade' a qual precisa aplicar sua 'universalidade') produz o sujeito sob a forma do sujeito de direito" (Pêcheux, 1997, p. 159).

O sujeito - ideológico - será constituído na evidência da norma identificadora que cria o efeito de dizer exatamente o que se diz, ao encobrir os sentidos ideológicos dos enunciados (Pêcheux, 1997).

Estima-se que o sujeito teria se suicidado única e exclusivamente pela doença, como um efeito de evidência de causalidade. Esse gesto 
isola, marginaliza o suicida, deposita nele a culpa e autoria de seu gesto, em uma relação de causa-efeito precisa, única e universal. A relação feita entre a doença e a morte encobre o elo realizado pelo trabalho entre o sujeito, o Outro ideológico do lugar social, e o outro próximo, colega ou cliente. Não deve ser uma tarefa simples servir café com as mãos trêmulas.

Adiante, o Caso 1 é o mais emblemático no sentido coletivo dos acontecimentos. Muitos fatores confluem na mesma "cena descrita" pelos depoentes e, ao final do processo, tudo parece confuso já que os depoimentos não coincidem uns com os outros. Ficam explícitas as relações de poder no caso da mulher: se trabalhadora, uma relação trabalhista; se amasiada, uma relação de dominação masculina em âmbito conjugal. Ainda assim, estão em jogo as relações de poder familiares, com a presença da mãe, estando a mulher no lugar de filha. Podemos supor que esta mulher era uma prostituta submetida ao seu patrão/amante, pois, segundo a perícia, ela tinha muitas marcas no corpo anteriores ao ocorrido.

Supondo que ela trabalhasse na pensão, independentemente de sua função, e que ali estavam presentes suas colegas de trabalho, eles não parecem ter para com ela nenhuma ação de solidariedade. Nenhum dos sete depoentes disse ter conhecimento do que se passava com a mulher. Se um suicídio acontece no local de trabalho, toda uma coletividade está sofrendo, mas havia mais pessoas na cena, o que dificulta a clareza da leitura. Mesmo sendo a intenção do judiciário encontrar possíveis cúmplices à morte, há uma falha no discurso dos depoentes ao terem acusado saber das aflições da suicida, o que remete às estratégias coletivas de defesa expostas por Dejours e Bègue.

Talvez, esta mulher tenha sido muito mais vítima de seu gênero do que sua classe ou ocupação laboral. Mesmo que admitíssemos que ela não trabalhava na pensão, qual a relação entre homem e mulher que ali se expressava, frente ao que foi quase uma plateia, se não a de dominação patriarcal? O seu patrão - e delatado amante - e a sua mãe também estavam no quarto quando ela fez o disparo. Aos olhos de Marx, sobre os suicídios realizados pelas mulheres no seu tempo, “o caso parece paradigmático do poder patriarcal absoluto dos homens sobre suas esposas e de sua atitude de possuidores zelosos de uma propriedade privada. [...] O marido tirânico é comparado a um senhor de escravos" (Marx, 2006, p.19).

De acordo com a perícia, a mulher tinha marcas no corpo anteriores à noite do suicídio. Cabem aqui os questionamentos de Heleieth Saffioti (1976), sobre a inferiorização da mulher enquanto uma necessidade estrutural do sistema capitalista ou uma tradição cultural. Qual lugar essa mulher ocuparia enquanto trabalhadora na pensão? Em consonância com Marx (2006), Saffioti (1976) afirma que a divisão por sexo serve para desviar a atenção da estrutura de classe, 
centrando-se nas características físicas de um grupo. Sendo a estrutura de classe e organização do trabalho limitativas das potencialidades humanas, é preciso renovar as crenças das limitações naturais das mulheres. Como bem demonstra o caso, em que as testemunham afirmam que a mulher era "perturbada", estava muito ansiosa quando do ocorrido e, a maior de todas as desqualificações por gênero, tinha ingerido vinho e estava em seu ciclo menstrual.

Se a mulher chamara a mãe para conversar na pensão, o que ela queria? O que o patrão/amante fazia no quarto? Como ela adquiriu ou de quem era a arma? Onde estavam as colegas? Cercada por toda a solidariedade e acolhimento possível - da mãe, do amante, das colegas - uma mulher se suicida. Mais do que uma denúncia endereçada, esse caso é um grito de isolamento.

O Caso 2 também foi escolhido pela sua singularidade. O suicídio de um homem desempregado e mais do que isso, caracterizado nos depoimentos como "boêmio". É preciso ressaltar que muitos fatores incidem sobre um desempregado, principalmente quando tratamos da questão de pertencimento social no Brasil da década de 1970. Esse período de fechamento político pela Ditadura Militar ainda sofria fortemente os reflexos das políticas trabalhistas da década de 1930.

No contexto da regulamentação das leis do trabalho cria-se a CLT (Consolidação das Leis do Trabalho) e a Carteira de Trabalho. Não cabe a este artigo discutir a competência das Leis Trabalhistas, mas sim, discutir a importância da criação da Carteira de Trabalho que, no período em discussão, equivalia-se a uma Carteira de Identidade e, assim, se manteve até a abertura política e Constituição de 1988. Ligar a identidade ao trabalho é reconhecer a população trabalhadora enquanto cidadã e, ao mesmo tempo, delimitar o que é e o que não é trabalho, segregando grupos. Ela dá e tira acesso.

Retomamos os apontamentos de Pêcheux (1997), onde é o “'semprejá-aí' da interpelação ideológica que fornece-impõe a 'realidade' e seu 'sentido' sob a forma de universalidade" (p. 164). O processo do "boêmio" traz a cena o não-lugar no mundo do trabalho. O não pertencimento à classe e, portanto, o desgosto do pai e da mãe. Nesse caso, não se encontra no processo um lugar determinado para este sujeito, nem esposo, nem trabalhador, nem filho querido.

É interessante perceber nos depoimentos que eles dizem não só daquilo que os depoentes querem falar, mas sobre o que a polícia quer saber. Buscou-se saber como o sujeito ocupava seu tempo, o que fazia, para onde ia, quais lugares costumava frequentar. Observamos ainda que o relato da mulher, ao apontar que não sabia se ele frequentava a Zona do Meretrício, indica o questionamento realizado. É nisso que este processo chama atenção, pois, nesse período, a cidadania ainda estava muito ligada ao vínculo empregatício e o inquérito especula sobre esse ser "vagabundo". Fica claro o eco das perguntas e a não espontaneidade nos depoimentos. 
Especificamente no caso do sujeito boêmio, se cria uma recusaresistência à norma identificadora do sujeito enquanto trabalhador, mas identifica-se o sujeito enquanto boêmio, ou seja, outra filiação do sujeito na ideologia. Os depoimentos colhidos no processo situam o sujeito na borda daquilo que é a normativa: se diz do sujeito que é comerciário e, ao mesmo tempo, são relatadas suas saídas, jogos, dívidas, desgosto para os pais.

A acusação, realizada pelos autores citados até agora, apontam o sintoma de uma organização social. O suicídio assinalaria uma ruptura desta cadeia. Morre-se para não submeter-se. Morre-se para denunciar. Pelo viés da Análise do Discurso, podemos fazer a leitura do gesto de suicídio enquanto autoria:

O autor é aqui uma posição na filiação de sentidos, nas relações de sentidos que vão se constituindo historicamente e que vão formando redes que constituem a possibilidade de interpretação. Sem esquecer que filiar-se é também produzir deslocamento nessas redes (Orlandi, 1996 p. 15).

O Caso 2 não é um exemplo de problema advindo do trabalho e sim do não-trabalho - que também não é desemprego - podem evidenciar um sujeito já desidentificado da estrutura social. Que tipo de questionamento pairava sobre ele e ele mesmo fazia frente à exclusão ou ao sentimento de não pertencimento?

\section{Considerações finais}

Marx analisa os processos do arquivista policial Peuchet, buscando uma compreensão social, para além de situações laborais específicas. Dejours e Bègue nos dão um panorama da gênese do sofrimento patogênico nas relações de trabalho. Buscamos, através dos três casos, realizar um diálogo com algo mais próximo. É possível que ressaltemos a estreita relação entre o olhar que Marx lança ao suicídio no século XIX e a proposta de Dejours e Bègue no século $X X I$. Se mudanças ocorreram, também muitas estruturas sociais de dominação se mantiveram adaptadas nestes 164 anos que separam as duas obras.

Compreendemos que o interesse do inquérito policial não é entender as esferas do suicídio e, em todos os casos - mesmo nos casos dos autores Dejours e Bègue (2010) e Marx (1846) - o discurso hegemônico tende para a culpabilização do sujeito.

O texto do judiciário é um espaço que joga com a ausência e com o não-sentido. Os depoimentos não andam em qualquer direção, são regidos por perguntas e respostas, são técnicos, rápidos. Vai-se ao local, ouvem-se as testemunhas, faz-se a perícia, enfim, o Estado 
cumpre o protocolo que lhe cabe e encerra as investigações. Buscamse apenas sujeitos que colaborem diretamente com a morte. Achar culpados, mesmo que a própria vítima. O que mais o judiciário, representante do Estado, pode fazer, a não ser seu papel burocrático?

O sujeito suicida é aquele que comete um ato isolado, ou por uma doença crônica, pelas reincidentes tentativas ou mesmo pela combinação entre ciclo menstrual e ingestão de vinho. Porém, ao mesmo tempo em que silencia e culpabiliza, o judiciário evidencia algo que falha. Desestabiliza os sentidos trazidos no próprio processo, ao tratar o morto como vítima abre o sentido da autoria social.

o suicídio é, em si, um gesto que, sendo uma forma de linguagem, produz significado, esse também passível de equívoco, onde os sentidos não se fecham, não são evidentes e abrem novos espaços para significação. Nos textos com os quais trabalhamos, podemos perceber a especificidade naturalizada que o Estado, representado pelo saber/ficção judiciário, dá a esses casos. É nesta trama que a ideologia se apresenta. O discurso judiciário pode ser pensado como um representante da ideologia dominante. Pêcheux (1997), a partir das concepções althusserianas de Aparelhos Ideológicos de Estado, afirma que a ideologia sempre orientará os interesses da classe aos quais servem. As conclusões judiciais expressam o retorno ao sujeito e, em seu revés, o silenciamento do sofrimento da classe, da organização do trabalho, das relações de poder desiguais entre gêneros, da validação social que o trabalho representa.

Compreendendo a ideologia como um ritual e partindo da premissa descrita por Pêcheux onde "não há ritual sem falhas" (1997, p.301), a ideologia não pode ser vista com um processo massivo. Ela interpela todos os sujeitos, mas falha. Estilhaça-se no lapso dos sentidos. Isso pode ser observado nos processos que tratamos no momento em que o morto é enunciado como "a vítima". A alteridade e o deslocamento produzidos pelo autor do suicídio ameaçam a estabilidade das estratégias coletivas de defesa, do condicionamento ao trabalho e de seus sentidos. E nesse gesto existe possibilidade de fuga dos sentidos, onde a "história trabalha seus equívocos, onde o discurso deriva para outros discursos possíveis" (Orlandi, 1996, p. 13).

Quando o processo trata o morto como vítima no discurso judicial, propomos que ali se evidencia, ao mesmo tempo, a autoria social e a autoria do sujeito. Autoria social ao passo que há algo exterior ao sujeito que o interpela. O sujeito se inscreve a partir de seu ato, como autor.

Se compreendermos que não há literalidade nas palavras, a metáfora está na base da significação: uma palavra por outra (Orlandi, 1996). O suicídio passa então a ser uma metáfora, onde o autor e a vítima correspondem. 
Esse sentido naturalizado e institucionalizado do texto do judiciário criminal, que chama todo o morto de vítima quebra o processo ideológico de culpabilização do sujeito. Instala-se um lapso nos sentidos. A ideologia, através do discurso judicial, falha, dizendo o que não pode ser dito, através do apagamento do autor, admite-se que o sujeito suicida é vítima. Ora, quem é vítima é vítima de alguém ou de algo. "Há uma contradição entre mundo e linguagem e a ideologia é trabalho desta contradição" (Orlandi, 1996, p. 31). Mas nesses casos, convive-se melhor com a sensação de dúvida do que com as afirmações finais e incoerentes das conclusões dos processos. Este trabalho aponta para (mais) uma compreensão dos sentidos sobre o suicídio, ato de complexidade ímpar que se desdobra em diferentes significações nas instâncias que o tangenciam: a saúde, a lei, o trabalho. Compreendemos que, mesmo remetendo aos anos 60 e 70, os casos analisados nos mostram as evidências de ambas as análises dos autores referenciados e constituem uma perspectiva para a cidade de Caxias do Sul, que em 2013 aponta como a terceira cidade em índice de suicídio no Rio Grande do Sul ${ }^{1}$. Esta perspectiva atemporal de silenciamento remete a uma constante.

No referencial abordado, a ideologia é tomada como elemento estrutural das relações humanas e de trabalho que se marca incessantemente, apontando para o mesmo do sentido, mas, de forma basculante, abrindo espaço para o heterogêneo. É por este movimento que salientamos a importância de trazer para o centro das discussões sobre o trabalho, a desconfortável temática do suicídio. Ato de linguagem que insiste em se fazer presente e denuncia a escassez de palavras daqueles que o tratam.

Há tantas possibilidades de desdobramento quanto há heterogeneidade da temática e dos pontos de vista do campo de origem dos autores. Do ponto de vista histórico, metodologicamente e teoricamente muito poderia ainda ser feito, tanto para dar conta do contexto socioeconômico da época na cidade de Caxias do Sul, quanto para pensar a legislação vigente e o funcionamento do aparelho judicial. Trazer a questão do suicídio para o centro dos estudos sobre trabalho implica no resgate àquilo que foi silenciado. Fotografias, bilhetes, depoimentos que tenham uma escuta aberta para novos sentidos, além daquele datado no tempo, o da interpretação policial, consistem em um material rico em possibilidades de análise. O desenvolvimento de uma nova análise do acervo do Memorial do Judiciário, agora em fase final de catalogação, permitiria seguir o rastro de processos levados a outras instâncias.

O ponto de união dos três casos neste estudo consiste na relação dos sujeitos com o trabalho. Contudo, cada sujeito apresenta uma psicodinâmica particular e delicada na forma de apresentar o sofrimento, o que poderia ser abordado na continuidade deste 
estudo, envolvendo outros gestos de leitura e interpretação, ampliando o referencial bibliográfico de base.

\section{Referências}

Barros, F. O. (1997). O Amor e a Lei: o processo de separação no tribunal de família. Psicologia, Ciência e Profissão, 17(3), 4047.

Chalhoub, S. (2001). Trabalho, lar e botequim: o cotidiano dos trabalhadores no Rio de Janeiro da belle époque (2 ed.). Campinas: UNICAMP.

Dejours, C., \& Bègue, F. (2010). Suicídio e Trabalho: o que fazer?. Brasília: Paralelo.

Marx, K. (2006). Sobre o Suicídio. São Paulo: Boitempo. (Trabalho original publicado em 1818-1883)

Orlandi, E. P. (1996). Interpretação: autoria, leitura e efeitos do trabalho simbólico. Vozes: Petrópolis.

Orlandi, E. P (1997). As formas do silencio: no movimento dos sentidos. Campinas: Editora da UNICAMP.

Orlandi, E. P (2001). Discurso e Texto: formação e circulação de sentidos. Campinas: Pontes.

Pêcheux, M (1997). Semântica e discurso: uma crítica à afirmação do óbvio. Campinas: Editora da UNICAMP.

Saffioti, H., \& Iara, B. (1976). A Mulher na Sociedade de Classes: mito e realidade. Petrópolis: Vozes.

\section{Endereço para correspondência}

\section{Luciene J ung de Campos}

Universidade de Caxias do Sul

Centro de Ciências Humanas e Sociais

Rua Francisco Getúlio Vargas, 1130, Petrópolis, CEP 95099-370, Caxias do Sul RS, Brasil

Endereço eletrônico: ljungdecampos@gmail.com

\section{Raquel Alquatti}

Universidade de Caxias do Sul

Centro de Ciências Humanas e Sociais

Rua Francisco Getúlio Vargas, 1130, Petrópolis, CEP 95099-370, Caxias do Sul RS, Brasil

Endereço eletrônico: r.alquatti@gmail.com

\section{Stefany Rettore Garbin}

Universidade de Caxias do Sul

Centro de Ciências Humanas e Sociais

Rua Francisco Getúlio Vargas, 1130, Petrópolis, CEP 95099-370, Caxias do Sul RS, Brasil

Endereço eletrônico: regarste@gmail.com

I smael Pereira

Universidade de Caxias do Sul

Centro de Ciências Humanas e Sociais 
Luciene Jung de Campos, Raquel Alquatti, Stefany Rettore Garbin, Ismael Pereira

Rua Francisco Getúlio Vargas, 1130, Petrópolis, CEP 95099-370, Caxias do Sul RS, Brasil

Endereço eletrônico: pereira.isma@gmail.com

Recebido em: 19/01/2015

Reformulado em: 07/10/2015

Aceito para publicação em: 22/10/2015

\section{Notas}

* Doutora em Estudos da Linguagem: Teorias do Texto e do Discurso PPGLET/UFRGS (2010) e professora do Centro de Ciências Humanas e do Programa de Pós-Graduação em Turismo - mestrado e doutorado na Universidade de Caxias do Sul.

** Graduada em Psicologia pela Universidade de Caxias do Sul (2015), mestranda do PPGLET/UFRGS em Teorias do Texto e do Discurso.

*** Graduada em História (2014) na Universidade de Caxias do Sul, Caxias do Sul. Mestranda do PPGLET/UFRGS em Teorias do Texto e do Discurso.

**** Graduado em Psicologia pela Universidade de Caxias do Sul (2016).

${ }^{1}$ Fonte: Site do Instituto Humanitas Unisinos. Recuperado em 22 de outubro, 2013, de: http://www.ihu. unisinos. br/entrevistas/28462-\%60\%60os-numeros-desuicidios-no-rio-grande-do-sul-assustam \% 60\% 60-entrevista-especial-com-ricardonogueira 